DOI: $10.15593 / 24111678 / 2016.02 .01$

УДК 504.05

М.В. Висков, Д.Г. Золотозубов

Пермский национальный исследовательский

политехнический университет, Пермь, Россия

\author{
БЕЗОПАСНАЯ ЭКСПЛУАТАЦИЯ \\ ОБЪЕКТОВ ЗАХОРОНЕНИЯ ОТХОДОВ \\ ПРИ ИСПОЛЬЗОВАНИИ ПРОТИВОФИЛЬТРАЦИОННЫХ \\ ЭКРАНОВ ИЗ ПРИРОДНЫХ МАТЕРИАЛОВ
}

\begin{abstract}
Приведены сведения о полигонах захоронения твердых коммунальных отходов, их воздействии на окружающую среду и элементах защиты для его предотвращения. Отмечено, что воздействие объектов захоронения отходов осуществляется на все компоненты окружающей среды (атмосферу, гидросферу, литосферу, растения и животных), однако одним из основных элементов, сдерживающим данное воздействие, является противофильтрационный экран, поскольку предотвращает проникновение стоков в подземные и поверхностные воды. Приведены типы противофильтрационных экранов, регламентируемые нормативно-технической документацией, а также природные и синтетические материалы, применяемые для их строительства. Рассмотрены возможности и условия разрушения экранов из природных и синтетических материалов и их последствия. Приведены механизмы изменения состава и свойств грунтов при взаимодействии с фильтрационными водами. Проведен анализ литературных источников, описывающих проведение экспериментов по замачиванию грунтов растворами различного химического состава с последующим определением прочностных и деформационных характеристик, и сделаны предположения о возможном изменении свойств противофильтрационных экранов из природных материалов. Описана последовательность подготовки образцов для проведения эксперимента, их количество и время взаимодействия с фильтрационными водами. Представлены результаты исследований по определению модуля деформации природных грунтов, используемых в качестве противофильтрационного экрана при взаимодействии с фильтрационными водами объектов захоронения коммунальных отходов. Сделаны выводы о степени изменения модуля деформации грунтов противофильтрационного экрана (природной влажности, водонасыщенных и провзаимодействовавших с фильтрационными водами в течение 2, 5, и 15 суток), а также возможности применения экрана из природных грунтов в современных условиях.
\end{abstract}

Ключевые слова: полигон ТКО, изменение свойств грунта, противофильтрационный экран, геохимические барьеры.

M.V. Viskov, D.G. Zolotozubov

Perm National Research Polytechnic University, Perm, Russian Federation

\title{
SAFE OPERATION OF LANDFILL SITES BY USING IMPERVIOUS SCREENS MADE OF NATURAL MATERIALS
}

The article presents information on the landfill disposal of solid municipal waste and their impact on the environment and security features to prevent it. It was noted that the effects of waste disposal sites is carried out on all components of the environment (atmosphere, hydrosphere, lithosphere, plants 
and animals), but one of the basic elements of preventing exposure is impervious screen, as it prevents the penetration of leachate in the groundwater and surface water. The types of impervious screens, regulated by normative and technical documentation, as well as natural and synthetic materials used for their construction. The opportunities and conditions for the destruction of screens from natural and synthetic materials, and their consequences. Shown change mechanisms composition and properties of soil in contact with leachate. Analyzed the literature describing experiments on soils soak solutions of different chemical composition, with subsequent determination of strength and deformation characteristics and assumptions are made about the possible change in the properties of impervious screens made of natural materials. It describes the sequence of sample preparation for the experiment, their number and the time of interaction with the leachate. The results of investigations to determine the modulus of deformation of natural soils used as impervious screen in contact with leachate municipal waste disposal facilities. The conclusions about the degree of change in deformation modulus of soil impervious screen (natural moisture water saturated and interacted with the leachate within 2, 5 and 15 days), as well as the possibility of using the screen of the natural soil in modern conditions.

Keywords: landfill, changing of soil properties, impervious screen, geochemical barriers.

Захоронение бытовых отходов на полигонах ТКО является самым широко применяемым способом обезвреживания отходов в Российской Федерации.

При строительстве, а также на эксплуатационном и постэксплуатационном этапах жизненного цикла полигона должны обеспечиваться все необходимые требования по защите окружающей природной среды от его воздействия.

Одним из главных путей воздействия полигона на окружающую среду является образование фильтрационных вод, соответственно, возникает необходимость защиты горных пород зоны аэрации, подземных и поверхностных вод от загрязнения.

Соблюдение качества окружающей среды в процессе эксплуатации полигона достигается благодаря наличию искусственного противофильтрационного защитного экрана, устраиваемого в основании полигона с дренажной системой сбора и удаления фильтрата или с помощью природных грунтовых материалов с низким коэффициентом фильтрации, залегающим в основании объекта. Преимущественно в качестве природного противофильтрационного материала выступают глинистые грунты.

Однако при устройстве экрана из природных материалов в процессе проектирования не учитывается возможное изменение свойств грунтов и возможное разрушение построенного массива отходов. Соответственно, возникает необходимость оценить степень изменения свойств грунтов основания полигонов захоронения бытовых отходов при их взаимодействии с фильтрационными водами и обосновать необходимую конструкцию экрана, обеспечивающего безопасную эксплуатацию объекта захоронения отходов [1]. 
Полигон представляет собой сложную инженерную систему, предназначенную для захоронения отходов и предотвращения распространения загрязняющих веществ в компоненты природной среды не только на эксплуатационном, но и на постэксплуатационном этапе жизненного цикла объекта.

Возможные виды воздействия полигона представлены на рис. 1.

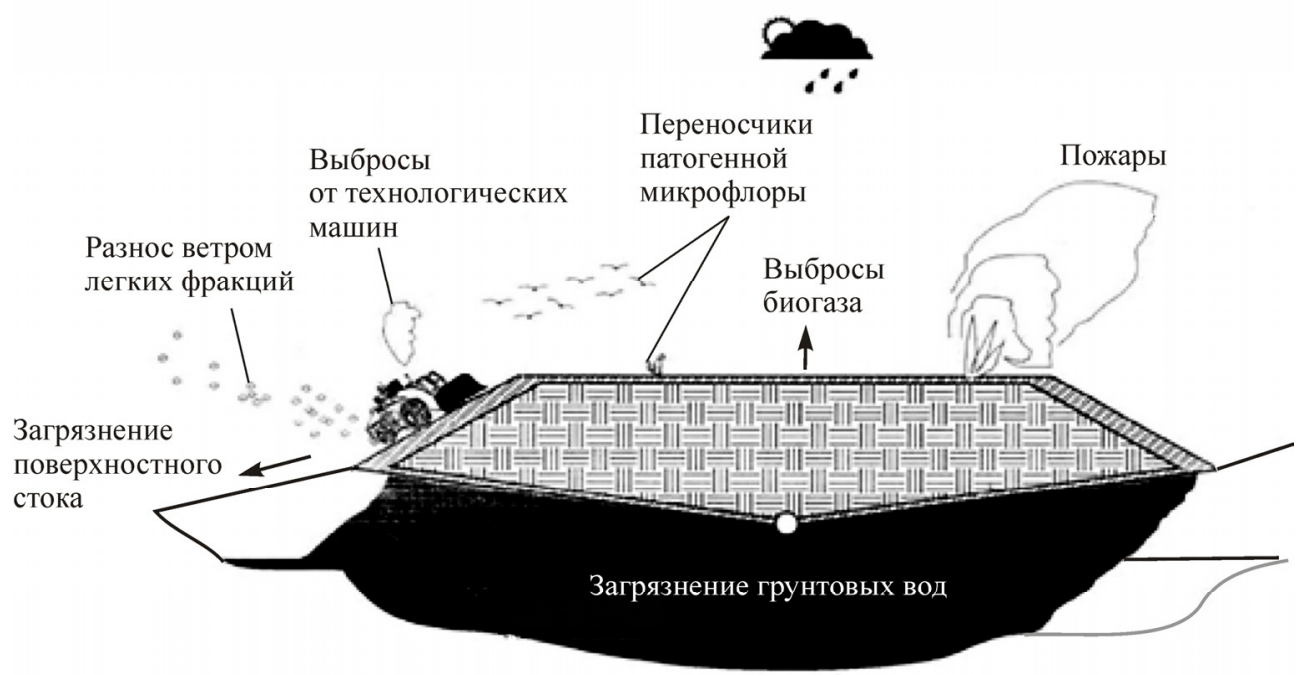

Рис. 1. Воздействие полигона захоронения ТКО на окружающую среду

Основным элементом, предотвращающим поступление загрязняющих веществ в грунтовые воды, является противофильтрационный экран. Дополнительно для снижения гидростатической нагрузки на экран устраивается дренажная система сбора и удаления фильтрата, которая позволяет удалить большую часть фильтрационных вод.

Одновременно грунтовое основание (или противофильтрационный экран) должно обеспечивать необходимую устойчивость массива захоронения отходов при любых вероятных воздействиях.

Противофильтрационные экраны, расположенные в основании полигона, можно разделить на две большие группы: из природных грунтов и искусственных материалов.

В качестве природного компонента преимущественно используется глина естественного залегания или привозная с послойной укладкой и уплотнением. Коэффициент фильтрации глины должен составлять не более $10^{-5} \mathrm{~cm} / \mathrm{c}[2]$. 
В качестве искусственного материала для строительства экранов могут применяться:

- асфальтобетон;

- асфальтополимербетон;

- бетон;

- железобетон;

- полимербетон;

- пленочные материалы;

- геосинететические материалы.

На практике достаточно часто применяют лишь последние два вида экранов из названных выше, однако самым дешевым является экран из глинистых грунтов естественного залегания. Использование экранов из природных материалов в последнее время не находит широкого применения ввиду сложности устройства искусственного экрана из привозного грунта и опасения проектировщиков относительно недостаточности обеспечения необходимых свойств для грунтов природного сложения.

Несмотря на высокие противофильтрационные свойства каждого из перечисленных материалов, в противофильтрационных экранах возможны условия, при которых может происходить проникновение загрязняющих веществ в подземные горизонты:

- для экранов из искусственных материалов - разрывы, разломы, нарушение сплошности, проколы и т.д.;

- для грунтов из природных материалов - изменение коэффициента фильтрации ввиду изменения состава и структуры при взаимодействии с фильтрационными водами.

Кроме того, при взаимодействии с фильтрационными водами, имеющими сложный химический состав, возможно изменение свойств грунтового массива в основании объекта захоронения отходов, которое неблагоприятно скажется на несущей способности, что может повлечь еще более катастрофические последствия для окружающей среды, чем просто проникновение загрязненных вод в подземные горизонты $[1,3]$.

Также, одновременно с проникновением загрязненных стоков в грунтовый массив, возможна инициация процесса очистки стоков (или инициация возникновения геохимического барьера) с помощью реализации следующих механизмов поглощения загрязнителей:

- механический процесс поглощения;

- физико-химическая обменная способность; 
- химическое взаимодействие фильтрационных вод и грунта;

- биологическая поглотительная способность;

- ионообменные свойства грунта;

- сорбционные свойства грунта.

В результате анализа данных литературных источников, полученных при проведении экспериментов по замачиванию грунтов растворами различного химического состава, можно сделать следующие выводы [1, 4-8]:

1. При взаимодействии с различными растворами (кислыми, щелочными, водой, сложными растворами специального состава) однозначно происходит изменение свойств грунтового массива (модуль деформации, коэффициент сцепления, угол внутреннего трения и т.д.).

2. Величина изменения зависит от состава раствора, в большинстве случаев при использовании нейтральных растворов изменение свойств грунта незначительно, а при использовании сильно-кислотных и сильно-основных может достигать до $30 \%$ и более от начального значения параметра (в обе стороны) [1, 4-7, 9-11].

Информация об изменении свойств грунтов, провзаимодействовавших с фильтратом полигонов захоронения бытовых отходов, в литературе не приводится, соответственно, в рамках данной работы были проведены лабораторные исследования грунтов, прореагировавших с фильтрационными водами, с целью определения модуля деформации, а в последующем - и остальных прочностных и деформационных характеристик.

Для проведения работ были подготовлены следующие образцы грунта:

- грунт естественной влажности;

- водонасыщенный грунт;

- грунт, провзаимодействовавший с фильтрационными водами в течение 2 дней;

- грунт, провзаимодействовавший с фильтрационными водами в течение 5 дней;

- грунт, провзаимодействовавший с фильтрационными водами в течение 15 дней.

Каждый опыт выполнялся серией из трех образцов.

Водонасыщение (насыщение фильтрационными водами) проводилось с помощью вакуумирования. Усредненный состав фильтрационных вод объектов захоронения бытовых представлен в таблице. 
Характеристика состава фильтрационных вод полигона ТКО [12]

\begin{tabular}{|c|c|c|}
\hline Наименование показателя & Значение & НП* \\
\hline $\mathrm{pH}$ & $8,2-8,5$ & $6,5-8,5$ \\
\hline Цветность, Цо & $300-400$ & 35 \\
\hline ХПК, мгО/дм ${ }^{3}$ & $680-1200$ & 30 \\
\hline БПК ${ }_{5}, \mathrm{мгO}_{2} /$ дм $^{3}$ & $180-220$ & 2 \\
\hline БПК, ХПК & $0,26-0,18$ & - \\
\hline Солесодержание, мг/дм ${ }^{3}$ & $4800-5900$ & 1000 \\
\hline Жесткость, мг-экв/дм ${ }^{3}$ & $19,6-23,6$ & 10 \\
\hline Хлориды, мг/дм ${ }^{3}$ & $1830-2500$ & 300 \\
\hline Фосфаты, мг/дм ${ }^{3}$ & $28,2--34,15$ & 0,05 \\
\hline Ион аммония, мг/дм ${ }^{3}$ & $140-152,5$ & 0,5 \\
\hline Нитриты, мг/дм ${ }^{3}$ & $0,43-0,53$ & 0,08 \\
\hline Нитраты, мг/дм ${ }^{3}$ & $8,6-10,1$ & 40,0 \\
\hline Железо (общее), мг/дм ${ }^{3}$ & $10-50$ & 0,1 \\
\hline Марганец (II), мг/дм ${ }^{3}$ & $2,77-3,5$ & 0,01 \\
\hline Хром (III), мг/дм ${ }^{3}$ & $0,01-0,019$ & 0,5 \\
\hline Свинец (II), мг/дм ${ }^{3}$ & $0,045-0,16$ & 0,01 \\
\hline Медь(II), мг/дм ${ }^{3}$ & $0,3-0,4$ & 0,001 \\
\hline Цинк (II), мг/дм ${ }^{3}$ & $0,8-1,3$ & 0,01 \\
\hline Фенол, мг/дм ${ }^{3}$ & $2,2-2,5$ & 0,001 \\
\hline n-Крезол, мг/дм ${ }^{3}$ & $0,8-1,19$ & 0,004 \\
\hline Бензол, мг/дм ${ }^{3}$ & $0,02-0,036$ & 0,5 \\
\hline Гуминовые соединения, мг/дм³ & до 100 & - \\
\hline
\end{tabular}

*НП - нормативные показатели - приведены для воды рыбохозяйственного назначения.

Проведенные исследования позволили получить следующие результаты: модуль деформации водонасыщенного грунта составляет 30,7 МПа, модуль деформации грунта естественной влажности 15,4 МПа. Модуль деформации грунта, насыщенного фильтрационными водами, повышается пропорционально периоду взаимодействия с фильтрационными водами (рис. 2).

В ходе исследований наблюдались колебания значения модуля деформации (для образца грунта, провзаимодействовавшего с противофильтрационными водами в течение 2 дней, получен модуль деформа- 
ции, равный 19,2 МПа, что составляет $62 \%$ от модуля деформации водонасыщенного грунта), однако при дальнейшем продлении срока взаимодействия грунта и фильтрационных вод модуль деформации увеличивался (21,9 МПа для грунта с 5-дневной выдержкой в фильтрате и 25,6 МПа для грунта с 15-дневной выдержкой в фильтрате) [13-16].

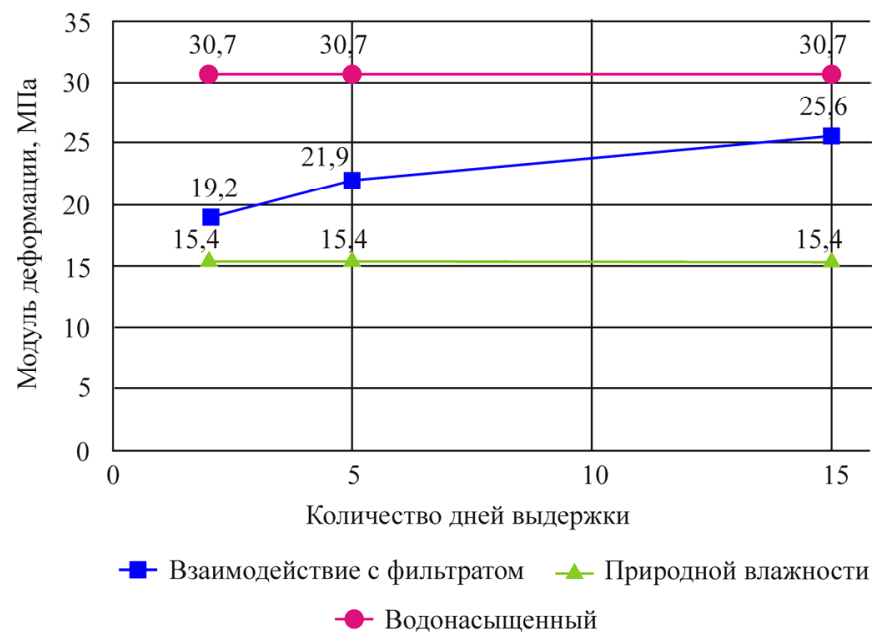

Рис. 2. Значения модуля деформации для грунтов противофильтрационного экрана с различными характеристиками

Таким образом, разница между модулем деформации водонасыщенного грунта и модулем деформации грунта, прореагировавшего с фильтрационными водами, составляет $17 \%$, однако можно сделать предположение о плавном повышении модуля деформации провзаимодействовавшего с фильтратом грунта до значений, близких к модулю деформации водонасыщенного грунта.

Учитывая специфику эксплуатации полигонов захоронения отходов (равномерное заполнение участка захоронения отходов и выход на проектную мощность в течение 5-15 лет), можно сделать вывод о достаточной прочности грунтов основания (или экрана) полигонов, даже при взаимодействии с фильтрационными водами.

Устройство экранов из природных материалов в настоящее время практически не используется при проектировании объектов захоронения отходов, поскольку у проектных организаций и надзорных органов сформировано неправильное представление об их эффективности и безопасности, однако такие экраны могут найти применение в строительстве небольших полигонов для малых населенных пунктов. 


\section{Список литературы}

1. Левченко А.П. Фундаменты и инженерные коммуникации сооружений на лессовых просадочных грунтах, насыщенных сточными водами: дис. ... д-ра техн. наук. - М., 2003. - 279 с.

2. Интенсивное использование территорий полигонов / В.Н. Коротаев, Н.Н. Слюсарь, М.В. Висков, Е.Ю. Буктеров, Ю.Н. Шлее // Твердые бытовые отходы. - 2010. - № 9. - С. 28-31.

3. Висков М.В. Использование свойств природных материалов для создания геохимических барьеров при строительстве объектов захоронения отходов // Вестник Пермского национального исследовательского политехнического университета. Прикладная экология. Урбанистика. - 2011. - № 4. - С. 122-129.

4. Максимович Н.Г. Безопасность плотин на растворимых породах (на примере Камской ГЭС). - Пермь: ООО ПС «Гармония», 2006. $212 \mathrm{c}$.

5. Морозов С.С., Васильева В.И., Дьячкова Н.Г. Изменение микроагрегатного состава и физико-механических свойств грунтов при взаимодействии с растворами солей, кислот и щелочей // В сб.: Вопросы инженерной геологии и грунтоведения. - Вып. 2. - М.: Изд-во МГУ, 1968. - C. 401-415.

6. Зиангиров Р.С. Оценка изменения инженерно-геологических свойств глинистых грунтов оснований при подтоплении промстоками // Процессы подтопления застроенных территорий грунтовыми водами (прогноз и защита): всесоюз. совещ. - Ч. 1. - Новосибирск, 1984. C. $18-20$.

7. Миронов В.С., Шаров В.И. Изменение физико-механических свойств лессовидных суглинков при их подтоплении // Процессы подтопления застроенных территорий грунтовыми водами (прогноз и защита): всесоюз. совещ. - Ч. 2. - Новосибирск, 1984. - С. 129-131.

8. Изучение свойств искусственных комбинированных материалов для проницаемых геохимических барьеров / Н.Н. Данченко, М.Л. Кулешова, З.П. Малашенко, Е.В. Петрова, В.И. Сергеев // Вестник Московского университета. Сер. 4. Геология. - 2011. - Т. 4, № 5. С. 54-60.

9. Евдокимова Л.А. Изменение химико-минерального состава глинистых грунтов при обработке их кремнийфтористо-водородной кислотой // Изменение геологической среды под влиянием деятельности человека. - М., 1982. - С. 28-32. 
10. Кульчицкий Л.И., Усьяров О.Г. Физико-химические основы формирования свойств глинистых пород. - М.: Недра, 1981. - 178 с.

11. Махорин А.А. Особенности развития геологических процессов под влиянием техногенных факторов. Теоретические основы инженерной геологии. Геологические основы / под ред. Е.М. Сергеева. М.: Недра, 1985. - С. 219-229.

12. Управление отходами. Сточные воды и биогаз полигонов захоронения твердых бытовых отходов: моногр. / Я.И. Вайсман [и др.]; под ред. Я.И. Вайсмана. - Пермь: Изд-во Перм. нац. исслед. политехн. ун-та, 2012. - 259 с.

13. Пособие по проектированию оснований зданий и сооружений (к СНиП 325 2.02.01-83). - М.: Стройиздат, 1986. - 416 с.

14. Сквалецкий Е.Н., Балаев А.Л., Воронина Д.А. Формирование инженерно-геологических свойств лессовых пород в условиях длительного увлажнения // Тр. ВНИИГиМ. - М., 1982. - С. 90-105.

15. Тер-Мартиросян 3.Г. Реологические параметры грунтов и расчеты оснований сооружений. - М.: Стройиздат, 1990. - 200 с.

16. Механика грунтов, основания и фундаменты / С.Б. Ухов, В.А. Семенов, В.В. Знаменский, З.Г. Тер-Мартиросян, С.Н. Чернышев. - М.: Изд-во АСВ, 1994. - 527 с.

\section{References}

1. Levchenko A.P. Fundamenty i inzhenernye kommunikatsii sooruzhenii na lessovykh prosadochnykh gruntakh, nasyshchennykh stochnymi vodami [Foundations and engineering communications of buildings in loess subsiding soils saturated with sewage]. Thesis of Doctor's degree, Moscow, 2003. 279 p.

2. Korotaev V.N., Sliusar' N.N., Viskov M.V., Bukterov E.Iu., Shlee Iu.N. Intensivnoe ispol'zovanie territorii poligonov [Intensive using of the landfill site]. Tverdye bytovye otkhody, 2010, no. 9, pp. 28-31.

3. Viskov M.V. Ispol'zovanie svoistv prirodnykh materialov dlia sozdaniia geokhimicheskikh bar'erov pri stroitel'stve ob"ektov zakhoroneniia otkhodov [Using the properties of natural materials for creation of geochemical barriers during landfill's objects construction]. Vestnik Permskogo natsional'nogo issledovatel'skogo politekhnicheskogo universiteta. Prikladnaia ekologiia. Urbanistika, 2011, no. 4, pp. 122-129. 
4. Maksimovich N.G. Bezopasnost' plotin na rastvorimykh porodakh (na primere Kamskoi GES) [Dam Safety on soluble breeds (on the example of the Kama hydroelectric power station)]. Perm': OOO PS "Garmoniia", 2006. 212 p.

5. Morozov S.S., Vasil'eva V.I., D'iachkova N.G. Izmenenie mikroagregatnogo sostava i fiziko-mekhanicheskikh svoistv gruntov pri vzaimodeistvii s rastvorami solei, kislot $\mathrm{i}$ shchelochei [Changing microaggregate composition and physico-mechanical properties of soil at interaction with solutions of salts, acids and alkalis]. Voprosy inzheneroi geologii i gruntovedeniia. Moskovskii gosudarstvennyi universitet, 1968, iss. 2, pp. 401-415.

6. Ziangirov R.S. Otsenka izmeneniia inzhenerno-geologicheskikh svoistv glinistykh gruntov osnovanii pri podtoplenii promstokami [Assessment of changes in geotechnical properties of clayey soils foundations during industrial effluent underflooding]. Vsesoiuznoe soveshchanie "Protsessy podtopleniia zastroennykh territorii gruntovymi vodami (prognoz $i$ zashchita)”. Novosibirsk, 1984, Part 1, pp. 18-20.

7. Mironov B.C., Sharov V.I. Izmenenie fiziko-mekhanicheskikh svoistv lessovidnykh suglinkov pri ikh podtoplenii [Changing the physical and mechanical properties of loess loam during their underflooding]. Vsesoiuznoe soveshchanie "Protsessy podtopleniia zastroennykh territorii gruntovymi vodami (prognoz $i$ zashchita)”. Novosibirsk, 1984, part 2, pp. 129-131.

8. Danchenko N.N., Kuleshova M.L., Malashenko Z.P., Petrova E.V., Sergeev V.I. Izuchenie svoistv iskusstvennykh kombinirovannykh materialov dlia pronitsaemykh geokhimicheskikh bar'erov [Studying the properties of artificial composite materials for permeable geochemical barriers]. Vestnik Moskovskogo universiteta. Seriia 4 "Geologiia", 2011, vol. 4, no. 5, pp. 54-60.

9. Evdokimova L.A. Izmenenie khimiko-mineral'nogo sostava glinistykh gruntov pri obrabotke ikh kremniiftoristo-vodorodnoi kislotoi [Changing the chemical and mineral composition of clayey soils at processing of silicon-hydrofluoric acid]. Izmenenie geologicheskoi sredy pod vliianiem deiatel'nosti cheloveka. Moscow, 1982, pp. 28-32.

10. Kul'chitskii L.I., Us'iarov O.G. Fiziko-khimicheskie osnovy formirovaniia svoistv glinistykh porod [Physical and chemical bases of properties formation of clay rocks]. Moscow: Nedra, 1981. $178 \mathrm{p}$.

11. Makhorin A.A. Osobennosti razvitiia geologicheskikh protsessov pod vliianiem tekhnogennykh faktorov. Teoreticheskie osnovy inzhenernoi 
geologii. Geologicheskie osnovy [Features of geological processes development under the influence of technogenic factors. Theoretical bases of engineering geology. Geology foundations]. Moscow: Nedra, 1985, pp. 219-229.

12. Vaisman Ia.I. [et al.]. Upravlenie otkhodami. Stochnye vody i biogaz poligonov zakhoroneniia tverdykh bytovykh otkhodov [Waste management. Sewage and biogas of landfill for solid domestic waste disposal]. Permskii natsional'nyi issledovatel'skii politekhnicheskii universitet, 2012, $259 \mathrm{p}$.

13. Posobie po proektirovaniiu osnovanii zdanii i sooruzhenii [Manual for the design of foundations of buildings and structures]. Moscow: Stroiizdat, 1986. 416 p.

14. Skvaletskii E.N., Balaev A.L, Voronina D.A. Formirovanie inzhenerno-geologicheskikh svoistv lessovykh porod $\mathrm{v}$ usloviiakh dlitel'nogo uvlazhneniia [Formation of engineering-geological properties of loess rocks in conditions of prolonged wetting]. Trudy VNIIGiM. Moscow, 1982, pp. 90-105.

15. Ter-Martirosian Z.G. Reologicheskie parametry gruntov i raschety osnovanii sooruzhenii [Rheological parameters of soils and calculations of structures foundations]. Moscow: Stroiizdat, 1990. 200 p.

16. Ukhov S.B., Semenov V.A., Znamenskii V.V., Ter-Martirosian Z.G., Chernyshev S.N. Mekhanika gruntov, osnovaniia i fundamenty [Mechanics of soils, bases and foundations]. Moscow: Assotsiatsiia stroitel'nykh vusov, 1994. $527 \mathrm{p}$.

Получено 30.05.2016

\section{Об авторах}

Висков Михаил Владимирович (Пермь, Россия) - старший преподаватель кафедры «Охрана окружающей среды» Пермского национального исследовательского политехнического университета (614990, г. Пермь, Комсомольский пр. 29, e-mail: mihail_viskov@list.ru).

Золотозубов Дмитрий Геннадьевич (Пермь, Россия) - кандидат технических наук, доцент кафедры «Строительное производство и геотехника» Пермского национального исследовательского политехнического университета (614990, г. Пермь, Комсомольский пр. 29, е-mail: spstf@pstu.ru). 


\begin{abstract}
About the authors
Mikhail V. Viskov (Perm, Russian Federation) - Senior Lecturer, Department of Environmental Protection, Perm National Research Polytechnic University (29, Komsomolsky av., Perm, 614990, Russian Federation, e-mail: mihail_viskov@list.ru).

Dmitrii G. Zolotozubov (Perm, Russian Federation) - Ph.D. in Technical Sciences, Associate Professor, Department of Construction Operations and Geotechnics, Perm National Research Polytechnic University (29, Komsomolsky av., Perm, 614990, Russian Federation, e-mail: spstf@pstu.ru).
\end{abstract}

